\title{
Model Development of School Database Management Information System
}

\author{
Ahmad Gawdy Prananosa ${ }^{1}$, Mochamad Wahyudi ${ }^{2}$, Suparno Eko Widodo ${ }^{3}$ \\ Correspondent Email: ahmadgawdy@stkippgri-lubuklinggau.ac.id \\ ${ }^{1}$ STKIP PGRI Lubuklinggau, Indonesia \\ ${ }^{2}$ STMIK Nusa Mandiri Jakarta, Indonesia \\ ${ }^{3}$ Universitas Negeri Jakarta, Indonesia
}

\begin{abstract}
The study aimed at analyzing the school management information system database. It used system development life cycle with spiral model approach. The Boehm spiral model was classified into four: concept, system and model developments, as well as system reparation cycles. Each cycle included needs analysis, planning, risk assessment, development, try-out and evaluation. The model development of school database management information system satisfied users. It was proved by the completeness of the system (logging, home, structure, completeness menu and submenu, graphic design and logout) with the average $95 \%$ satisfying users' needs. The school database included home profile, students, instructors and education, finance, facilities and infrastructure, reports, and logging with the average of $97 \%$ meeting users' needs.
\end{abstract}

Keywords: Model Development, School SIM Database

\section{Introduction}

Technology is intended to facilitate the work, facilitating practical, fast and accurate approach to tasks. Information technology can access and display latest data such as web-based information technology in which presents information either in form of text, still or moving picture, animations, sound, and video. Lee and Owens stated that the success of web development relies on 1) developer creativity and ability, 2) bandwidth and 3) hardware capabilities [1].

Web design requires creativity in forming the interface, menu components, color selection and animation features. According to Lightfoot, web display results help students get the required material [2]. The results of the research Dubas, Pressly and Hill showed that the most important part aspect of web is the design and content which simplifies communication. Quick access capability aims to avoid errors in downloading or uploading processes [3] . The hardware (processor, RAM and hard disc) should be able to facilitate speed in gathering information and avoiding failures in accessing data.

Information-based website technology can be utilized by educational institutions in providing quick and precise access to services by communities and stakeholders. Organization of school management information system can be by means web-based information technology. A new era of education introduced reforms that are closely related to information systems for development. 
A school has several components including facilities and infrastructure, curriculum, instructors and staff, students, finance, and public relations. The school components can be managed through a website-based management information system for data to be managed integrally. The results of Kamile's study on school management information systems was significant in this regard [3]. In addition, the results of a research by Shoonwan indicated that an effective education management information system should meet the criteria of accessibility, be explicit and fit in with the existing needs [4] [5] [6]. According to Fichman, Santos and Zheng , digital innovation and information technology can be a solid foundation in managing organizations [3]. The development of digital innovation can provide an online display (CCTV) in recording images from a considerable distance. This makes it important for managers or top leaders to monitor the manner in which employees carry out their duties and responsibilities.

Similarly, Demmisie and Rorissa established that implications of the use of information technology has significant impacts on decision makers [6] . Good school data management supports decision makers; in this case, the Head of Education Office, and facilitates the development of schools. The data displayed can provide information to the head of the Education Office and helps in making decisions when it comes to improving the quality of education. The Education Office seeks to manage the data components appropriately, a function that can be facilitated by a web-based school management information system.

\section{Methodology}

The research used life cycle system development approach of spiral model divided into 4 cycles i.e.: 1) concept development cycle, 2) system development cycle, 3) model development cycle, and 4) system improvement cycle. Each cycle includes needs analysis, planning, risk assessment, development, testing and evaluation.

\subsection{Stage of Needs Analysis}

The stage consists of initial data collection and needs analysis. The former was conducted to obtain relevant concepts and research results that could strengthen the concept of the study. Observation and interviews were done on the Heads of institutions (School Principals, Supervisors and KUPT) as well as the school operators, profile data collection, vision and mission of Education Office of Musi Rawas Utara

\subsection{Planning Stage}

At the planning stage, the researcher determined the purpose, the aspect of database management to be developed in the school management information system; the procedures, and then designed the basic concept of school management information system that needed to be established. This was identified by designing school databank in form of menu structure design describing the designed system and sub system in the school database management information

system, as well as flowchart data. The proceeding step involved preparing developer resources 
(database programmer and website designer), time schedule, and supporting tools such as software programming language PHP and MSQL.

\subsection{Stage of Risk Analysis}

This stage analyzed the risks that occur when designing school database management information system model. The school database consist several components. Each component was appropriate to be developed requires risk analysis. Each school database component was considered to feasibility to be displayed in general or not, it will have a great or no risk to school if it is going to be developed. The next step was analyzed the strength of database server capacity and bandwidth, so that database applications may run properly.

\subsection{Development Stage}

At this stage, the researcher built a prototyping by creating a temporary design focusing on the presentation to the user (e.g. by making input and output format). The school components to be developed were as follows: 1) educators and teachers, 2) students 3) facilities and infrastructure, 4) finances, involving data on receipt of funds and expenditure, 5) curriculum encompassing annual and semester programs, and subject schedules, and 6) public relations.

\subsection{Testing Stage}

At this stage, an expert judgment, small group try-out, and field try-out were conducted as follows;

1. Expert Judgment. The results of the design and draft and the product of engineering information systems database management on the first draft was developed on the basis of the evaluation by the experts. Two experts conducted the review, a design and a database programmer professionals based on the 5 principles; accessibility, readability, speed, content, and technology.

2. Small Group Try-out. A small group try-out was performed on users consisting of 6 - 15 members. This small group represented the actual users. The goal was to determine the utility of product development in the users' groups. The results of the questionnaire distribution and project portfolio of performance at this stage were used to revise and improve the quality of the development product.

3. Field try-out. Field try-out was the final evaluation to be executed after the validation and revision in the previous phase. Field trials were conducted to around 30 people. At the time, the distribution of questionnaires, interviews and observation of field try-out activities was done to obtain as much information as possible related to the developed product.

\subsection{Evaluation Stage}

At this stage, evaluation techniques were used in the development of school database management information system models. They include; 1) The questionnaire distributed during the try-out to determine the level of user satisfaction with the evaluation of the school database 
management information system model, 2) interviewing users was meant to find out the completeness of the management information system database such as menu design and submenu components, 3) observation was done to determine the ease of users in utilizing the design of school database management information system model.

\section{Results And Discussion}

\subsection{Needs Analysis}

The results of the initial survey of the data management of students, teachers and facilities, and infrastructure showed the use the manual system. The average of respondents answering yes was $95 \%$, supporting the management of student data, teachers, and school infrastructure manually executed.

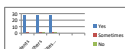

Fig 1. Need Analysis

Manual data management impedes the performance of school management practices such as 1) teachers data, students, and facilities and infrastructure tracking, requiring document tracing, an exercise that requires more time, 2) difficulties in reporting the developments, specifically the due to the distance to the Department of Education and Culture, spending time, extra costs and manpower, just to provide data on the progress and 3) manual storage of data is at risk of flood events, fire, and damage by animals (termites, cockroaches or insects) that can interfere with data stored in paper-based documents.

\subsection{Development of Concept}

The concept of developing the components of school data is based on Ministry of national education law (Permendiknas) Number 192007 on Education Management Standards by Primary and Secondary Education division. The school database components produced, can be explained specifically as follows:

1. The database of educators and the entire education consists of teachers and employees data (name, NUPTK, gender, place and date of birth, NIP, employee status (civil servant, TKS, 
Honorer), address, type of TOD, latest education, goals/space, date of the latest decree, start of duty, teaching in class), teachers and employees mutations (reason of mutation, origin and destination of school), teachers and employees development (activity names, date / month / year of activity, place of activities and results of activities)

2. Students database consists of students data (students' biography (name, gender, place and date of birth, religion, nationality, number of siblings, blood group and address), registration and national registration numbers), parents data (parents' names (father and mother), highest education level and occupation, school-leaving status, graduation (year of graduation, number of graduation certificate and continuing to school), and transfer from schools.

3. Database of facilities and infrastructure consists facility data (inventory code, type (furniture / school supplies), condition (good, moderate / severe damage), infrastructure data (name of space, amount of space, area (m2), medium / heavy damage), description)

4. Financial database consists revenue data including date / month / year, source of funds (central BOS, Free from Province, Free from Regency), amount, expenditure (graduate competition development, standard content, process standards, TOD, means and infrastructure, management standards, financing standards, implementation and assessment systems) total.

5. The curriculum database consists of annual and semester programs (theme, week number, activity schedule and description), as well as subject schedule (day, hour, subject and teachers names)

6. The public relations database consists school data (school name, NPSN, education level, address, date of establishment decree, date of operational license, bank name and account number, land area and NPWP, telephone, email, website, time organizers, ISO certification, electricity and internet access), school profile (vision and mission of programs, student and teacher achievement), and cooperation activities (date / month / year of activity, name of activity, partner agency and activity result)

\subsection{System Development}

School database management information system consists of department of education and school administrators. Each administration was developed with an online system and therefore the departments are able to input, process, and output the data online. The input, process and output of the school database management information system is as follows:

1. Department of education administration includes; data input (profile input and administration), processing (details, deletion, and change), and reports (students, educators and education, facilities and infrastructure, curriculum, school and finance).

2. School Administration consists of; Input data (input profile, student, educator and education, facilities and infrastructure, curriculum, cooperation, and finance), data process (detail, delete, and change) and reports (student, educator and education, facilities and infrastructure, curriculum, school, finance).

\subsection{Model Development}

Through school database management information system, all data is managed integrally and managed through database program. They are also stored in a server, so that data can be stored 
safely, neatly and able to avoid the risk of damage. Each school can provide monthly reports of school progress online, so it is not a time consuming and distance will not be a matter in the process of transferring data from school to the Department Education of North Musi Rawas District. Furthermore, it is beneficial especially for the Head of Education and Culture in mapping the condition of the school as well as the basis in a decision making to improve the quality of education in North Musi Rawas District of South Sumatra.

\subsection{Model Improvement}

Completed SIM database application consists of 6 items: a) login, b) home menu, c) menu and submenu structure, d) completeness of menu and submenu, e) graphic design, f) logout. Details description is presented in the graph below.

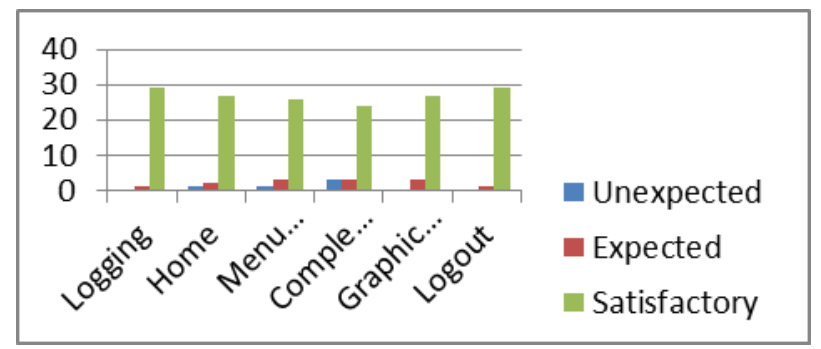

Fig 2. Completeness of SIM Application

From the graph above, it is evident that the structure and menu and submenu satisfy the SIM users of the school database. This also holds for the completeness of the menu and submenu SIM database. Moreover, the logging, home and logout menus satisfy the schools SIM database users while the graphic design menu has contents the SIM operators of the school databank. Therefore, the completeness of school database management information system applications satisfies users.

The management of the school database consists of 10 items including: a) home, b) profile, c) students database, d) database of educators and education, e) financial database, f) database of facilities and infrastructure, g) curriculum database, $h$ ) public relations database, i) database reports, and j) logging. The detailed description is presented in the following graph. 


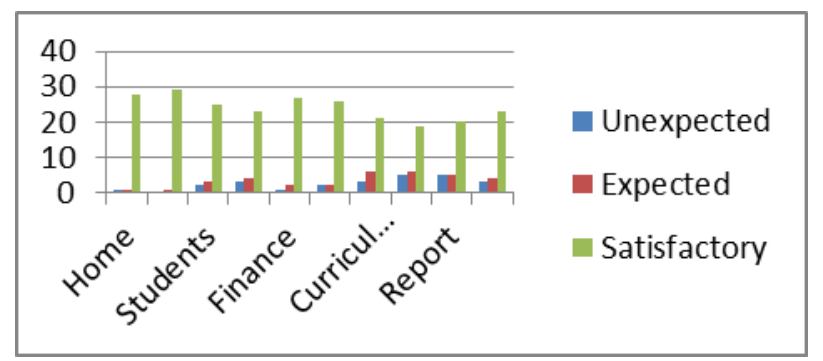

Fig 3 School Database

From the graph, it is evident that the management of home database, profile, students, educators and education, finance, facilities and infrastructure, curriculum, public relations, report, and logging satisfy the users of school database management information system. It can therefore be concluded that the controlling of the school users' database satisfies the operators of the school database management information system.

\section{Conclusion}

The development of school database management information system model satisfy the users. This is proved by the completeness of school application of database management information system (logging menu, home, menu structure, completeness of menu and submenu, graphic design and logout), and with the average 95\%, it meets users' needs. The school databases (home, profile, student, educator and education, finance, facilities and infrastructure, curriculum, public relations, reporting and logging) having the average of $97 \%$ also satisfies.

\section{References}

[1] Dawit Demmisie dan Abebe Rorissa.: The Effect of Information Quality and Satisfaction on a Parent's Behavioral Intention to Use a Learning Community Management System. Journal Libri, 65(2), $143(2015)$

[2] Fichman, Robert G, B. L. D. S. and Z. Z.: Digital Innovation As a Fundamental and Powerful Concept in The Information System Curriculum. Journal MIS Quarterly, 38(2), 78. (2014)

[3] Jay M. Lightfoot:: A Web-Based Knowledge Management Tool Utilizing Concept Maps for On-Line Student Advising. Journal of International Technology and Information Management, 23(1), 41 (2014)

[4] Kamile Demir.: School Management Information Sytem in Primary Schools. The Turkish Online Journal of Educational Technology, 5(2), 32 (2006)

[5] Khalid M. Dubas, R. P. and D. H.: The effectiveness of the website of four-year Collages and Universities in North Carolina. Proceedings of the Academy of Educational Leadership, 12(2), 55 (2012)

[5] Lee, W. W. dan D. L. O.: Multimedia-Based Instructional Design. San Fransisco: Pfeifer (2004)

[6] Soonhwan.: Evaluation Creteria For The Educational Web-Information Sytem. Journal the Quarterly Review of Distance Education, 9(2), 197 (2008) 


\section{Link osf}

https://osf.io/pzbys/?view_only=e3cd455ca8564e658fc014f222ffc31b 